\title{
Investigation of Antibiotic Use at a Dental Teaching Hospital in Yogyakarta, Indonesia: A Review from Guidelines
}

\author{
Mayu Winnie Rachmawati, Naoko Yoshida, Hirohito Tsuboi, Kazuko Kimura \\ Department of Drug Management and Policy, Graduate School of Natural Science and Technology, Kanazawa \\ University, Kanazawa, Japan \\ Email: mayuwinnie@ugm.ac.id
}

Received 10 March 2014; revised 25 April 2014; accepted 15 May 2014

Copyright @ 2014 by authors and Scientific Research Publishing Inc.

This work is licensed under the Creative Commons Attribution International License (CC BY). http://creativecommons.org/licenses/by/4.0/

\section{Open Access}

\section{Abstract}

Objective: To investigate prescription of antibiotics by dental practitioners at a dental teaching hospital in Yogyakarta, Indonesia, and to establish whether it conforms to major guidelines. Methods: A cross-sectional study of adult outpatients' medical records was conducted in order to scrutinize antibiotic prescriptions. The results were compared with recommendations in four published guidelines. Results: Dental practitioners prescribed a wide range of antibiotics to treat 121 diagnoses. Amoxicillin (78.8\%) was most commonly prescribed, followed by clindamycin (9.9\%), metronidazole $(5.0 \%)$, and lincomycin (2.1\%). Among all prescriptions, $79.5 \%$ were for generic antibiotics. The most common diagnoses were dental pulp gangrene followed by dental pulp necrosis $(26.7 \%$ and $8.8 \%$, respectively). According to guidelines-1 through-4, the percentages of antibiotic prescriptions that were evaluated as appropriate for the reported diagnosis were $15.1 \%, 7.2 \%, 7.5 \%$, and $16.3 \%$, respectively. However, $9.9 \%, 84.0 \%, 83.7 \%$ and $67.8 \%$ of prescriptions could not be classified as appropriate or inappropriate because the respective guidelines neither listed the antibiotic nor gave statement regarding appropriate indications. Conclusion: Our results suggest that significant inappropriate antibiotic prescribing occurred at a dental teaching hospital in Yogyakarta, Indonesia, according to major antibiotics guidelines. However, the four guidelines failed to list some antibiotics, failed to list indications for prescription in some cases, and were inconsistent in their recommendations. There is a need to introduce specific institutional guidelines. Our findings should be helpful for developing public health policy guidelines to minimize inappropriate antibiotic prescribing at dental hospitals.

\section{Keywords}

Appropriateness, Antibiotics Prescriptions, Dental Teaching Hospital, Guidelines 


\section{Introduction}

Antibiotics are widely used in dental practice to treat bacterial infections in the oral cavity, and approximately $80 \%$ of prescriptions are written in hospitals [1]-[3]. In addition, some dental practitioners prescribe antibiotics to patients prior to dental procedures, though there is little evidence that such prophylaxis is effective [4]. It is important to ensure appropriate antibiotic use, because inappropriate choice of antibiotics or use of antibiotics in unwarranted clinical situations could result in undesirable side effects and promote antibiotic resistance [5]. Further, there is evidence that dental practitioners often prescribe antibiotics for the management of oral and dental infections empirically, guided by their personal experience and knowledge [6]. Although inappropriate use of antibiotics has been a matter of global concern for many years, there have still been only a few studies about inappropriate use of antibiotics in developing countries [7], especially as regards different pharmacological subgroups. There are a number of established guidelines for the proper use of antibiotics, including Dentists' Drug and Prescription Guide [8], Drug Prescribing for Dentistry [9], Antibiotic Prescribing Guidelines for Dentists [10], and National Guideline Clearinghouse [11]. However, it is important to establish whether or not dental practitioners routinely comply with these guidelines, and whether the guidelines are adequate.

\section{Method}

A cross-sectional study was performed using data from the medical records of adult outpatients registered at the Prof Soedomo Dental Teaching Hospital, Universitas Gadjah Mada, during January-December 2010. The information collected included the age and sex of patients, antibiotic prescribed, dose (strength of antibiotic), frequency, duration (days), total quantity of antibiotic, diagnosis of chief complaint, and prescriber. All data were fully anonymized to protect the privacy of patients. This study was approved by the Ethics Committee of Kanazawa University and the Ethics Committee of the Medical Faculty, Universitas Gadjah Mada.

Appropriateness was evaluated according to four international major guidelines on the antibiotic treatment of dental infection: Dentists' Drug and Prescription Guide [8], Drug Prescribing for Dentistry [9], Antibiotic Prescribing Guidelines for Dentists [10], and National Guideline Clearinghouse [11]. These are designated as guideline-1 through-4, respectively, hereafter. We defined antibiotic use as inappropriate when one or more of the guideline requirements regarding indications for use, dosage and duration of treatment, general health history, or type of drug was not met.

The number of outpatients prescribed each antibiotic, the number of antibiotics per prescription, the number of generic antibiotics prescribed, and the number of non-generic antibiotics prescribed were coded on a Microsoft Excel ${ }^{\circledR}$ spreadsheet and analyzed. Note that all percentages are given to one decimal place, so totals may not add up to $100 \%$.

\section{Results}

Analysis of 16,847 medical record sheets from 2628 outpatients indicated that 2024 prescriptions for antibiotics had been issued during 2011. There were more male patients (55.7\%) than female patients (48.3\%). The mean ages for males and females were $30.7 \pm 13.7$ and $32.0 \pm 14.1$ years, respectively.

A total of 13 different antibiotics were prescribed. This included generic drugs (79.5\%) and branded/proprietary named drugs (20.5\%). Table 1 showed that the most frequently prescribed antibiotic was amoxicillin (78.8\%), followed by clindamycin (9.9\%). Metronidazole, lincomycin, and ciprofloxacin accounted for 5.0\%, $2.1 \%$, and $1.5 \%$, respectively.

Overall, 121 diagnoses were recorded for which antibiotics had been prescribed. Figure 1 summarized the diagnoses according to hospital department. Pulp gangrene was the most common diagnosis (26.7\%), followed by pulp necrosis (8.8\%), radices (6.1\%), periodontitis (5.8\%), and impacted molars (6.4\%).

Table 2 summarizes the prescribers of the drugs. It is noteworthy that co-assistants (dental students who may write prescriptions under supervision) accounted for $40.2 \%$ of all prescriptions.

Table 3 showed the percentages of appropriate use of antibiotic for each diagnosis according to guideline- 1 [8]. Only $15.1 \%$ of antibiotic prescriptions were identified as appropriate, while $66.3 \%$ were inappropriate, and 9.9\% could not be classified. Of the inappropriate prescriptions according to this guideline, $54.1 \%$ were for amoxicillin. According to guideline-2 [9], $7.2 \%$ of antibiotic prescriptions were appropriate and $0.1 \%$ were inappropriate, while 84.0\% could not be classified (Table 4). As shown in Table 5, according to guideline-3 [10], 
$7.5 \%$ of prescriptions were appropriate, $0.2 \%$ wereinappropriate, and $83.7 \%$ could not be classified. According to the guideline-4 [11] (Table 6) 16.3\% of prescriptions were appropriate, $7.26 \%$ were inappropriate and $67.8 \%$ could not be classified.

\section{Discussion}

Antibiotic prescription for focal infection is common practice in the dental profession [12] and is often used to complement local treatment, e.g. debridement, scaling, drainage, or surgery, especially for treatment for periodontal diseases and peri-implantitis [13]. However, guidelines may not be consistent or adequate to evaluate actual usage. Here, we aimed to investigate prescription of antibiotics by dental practitioners at a dental teaching hospital in Yogyakarta, Indonesia, and to examine its conformity with four major guidelines [8]-[11].

In this dental teaching hospital, prescriptions may be written by general dentists, residents (specialist dentists in training), dental specialists, and co-assistants (students of dentistry). Co-assistants may prescribe drugs including antibiotics under supervision. We found that $40.2 \%$ of prescribers were co-assistants. Thus, there may be an issue over proper supervision of prescribing by co-assistants, who may be unduly influenced by patients' requests for a particular drug. In any case, almost all antibiotic prescribing was empirical, because dental practitioners generally did not know the identity of the causal microorganism. Cultures and sensitivity testing were

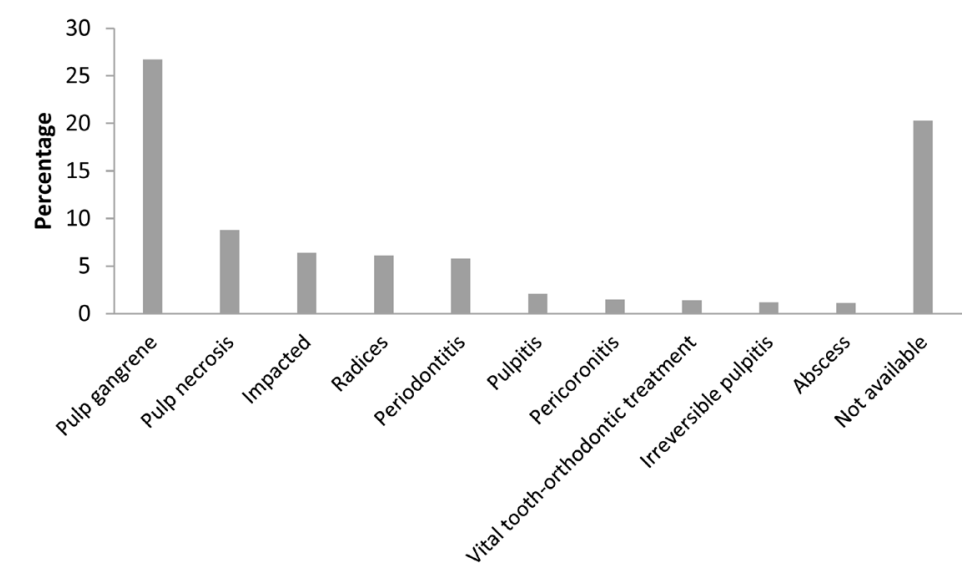

Figure 1. Most common diagnosis associated with antibiotic prescription.

Table 1. Most commonly prescribed antibiotics at the dental teaching hospital from JanuaryDecember $2011(\mathrm{~N}=2024)$.

\begin{tabular}{ccc}
\hline Antibiotics & Frequency of prescription & Percentage (\%) \\
\hline Amoxicillin & 1596 & 78.8 \\
Clindamycin & 201 & 9.9 \\
Metronidazole & 102 & 5.0 \\
Lincomycin & 42 & 2.1 \\
Ciprofloxacin & 30 & 1.5 \\
Spiramycin & 25 & 1.2 \\
Erythromycin & 18 & 0.9 \\
Cefadroxil & 2 & 0.1 \\
Cephalosporin & 2 & 0.1 \\
Doxycycline & 2 & 0.1 \\
Tetracycline & 2 & 0.1 \\
Ampicillin & 1 & 0.1 \\
Chloramphenicol & 1 & 0.1 \\
Total & $\mathbf{2 0 2 4}$ & $*$ \\
\hline
\end{tabular}

*Percentages are given to one decimal place, so the total is not $100 \%$. 
Table 2. Frequency of antibiotic prescribers.

\begin{tabular}{|c|c|c|c|c|c|c|}
\hline \multirow{2}{*}{ Antibiotic } & \multicolumn{6}{|c|}{ Prescribers N (\%) } \\
\hline & Dental specialist & Resident & Co-assistant & GDP $^{*}$ & No prescriber data** & Total \\
\hline Amoxicillin & $200(10.8)$ & $282(15.2)$ & 716 (38.6) & $284(14.0)$ & $114(5.6)$ & 1596 (78.9) \\
\hline Ampicillin & - & - & $1(0.1)$ & - & - & $1(0.1)$ \\
\hline Cefadroxil & $1(0.1)$ & $1(0.1)$ & - & - & - & $2(0.1)$ \\
\hline Cephalosporin & - & - & $1(0.1)$ & $1(0.1)$ & - & $2(0.1)$ \\
\hline Chloramphenicol & - & - & $1(0.1)$ & - & - & $1(0.1)$ \\
\hline Ciprofloxacin & $3(0.2)$ & $15(0.7)$ & $1(0.1)$ & $5(0.3)$ & $6(0.3)$ & $30(1.5)$ \\
\hline Clindamycin & $30(1.6)$ & $54(2.7)$ & $51(2.5)$ & $55(2.7)$ & $11(0.5)$ & 201 (9.9) \\
\hline Doxycycline & - & - & - & $2(0.1)$ & - & $2(0.1)$ \\
\hline Erythromycin & - & $3(0.2)$ & $9(0.4)$ & $3(0.2)$ & $3(0.2)$ & $18(0.9)$ \\
\hline Lincomycin & $8(0.4)$ & $15(0.7)$ & $12(0.6)$ & $6(0.3)$ & $1(0.1)$ & $42(2.1)$ \\
\hline Metronidazole & $11(0.6)$ & $17(0.8)$ & $18(0.9)$ & $29(1.4)$ & $27(1.3)$ & $102(5.0)$ \\
\hline Spiramycin & $12(0.7)$ & $1(0.1)$ & $3(0.2)$ & $5(0.3)$ & $4(0.2)$ & $25(1.2)$ \\
\hline Tetracycline & - & $1(0.05)$ & - & - & $1(0.1)$ & $2(0.1)$ \\
\hline Total & 265 (13.1) & 389 (19.2) & $813(40.2)$ & 390 (19.3) & $167(8.3)$ & $2024^{* * *}$ \\
\hline
\end{tabular}

${ }^{*}$ GDP: General Dental Practitioners; ${ }^{* *}$ Prescriber not mentioned in medical records; ${ }^{* * *}$ All percentages are given to one decimal place, so the total is not $100 \%$.

Table 3. The appropriateness of antibiotic prescriptions according to guideline-1.

\begin{tabular}{|c|c|c|c|c|c|c|c|}
\hline \multirow{2}{*}{ Antibiotic } & \multirow{2}{*}{$\begin{array}{c}\text { Appropriate } \\
\text { N (\%) }\end{array}$} & \multirow{2}{*}{$\begin{array}{c}\text { Inappropriate } \\
\text { N (\%) }\end{array}$} & \multicolumn{4}{|c|}{$\begin{array}{l}\text { Could not be classified } \\
\text { (Indeterminate: Id) }\end{array}$} & \multirow{2}{*}{$\begin{array}{l}\text { Total } \\
\text { N (\%) }\end{array}$} \\
\hline & & & Id $^{*}$ & $\mathbf{I d}^{* *}$ & $I d^{* * *}$ & $\mathbf{I d}^{* * * *}$ & \\
\hline Amoxicillin & 219 (10.8) & 1095 (54.1) & - & 159 (7.9) & - & $123(6.1)$ & 1596 (78.9) \\
\hline Ampicillin & - & $1(0.1)$ & - & - & - & - & $1(0.1)$ \\
\hline Cefadroxil & $1(0.1)$ & $1(0.1)$ & - & - & - & - & $2(0.1)$ \\
\hline Cephalosporin & - & $2(0.1)$ & - & - & - & - & $2(0.1)$ \\
\hline Chloramphenicol & - & $1(0.1)$ & - & - & - & - & $1(0.1)$ \\
\hline Ciprofloxacin & $12(0.6)$ & $12(0.6)$ & - & $3(0.2)$ & - & $3(0.2)$ & 30 (1.5) \\
\hline Clindamycin & 39 (1.9) & $120(5.9)$ & - & $22(1.1)$ & - & $20(1.0)$ & 201 (9.9) \\
\hline Doxycycline & $1(0.1)$ & $1(0.1)$ & - & - & - & - & $2(0.1)$ \\
\hline Erythromycin & $2(0.1)$ & $15(0.7)$ & - & $1(0.1)$ & - & - & $18(0.9)$ \\
\hline Lincomycin & $6(0.3)$ & $27(1.3)$ & - & $5(0.3)$ & - & $4(0.2)$ & $42(2.1)$ \\
\hline Metronidazole & $17(0.8)$ & $53(2.6)$ & - & $9(0.4)$ & - & $23(1.1)$ & $102(5.0)$ \\
\hline Spiramycin & $8(0.4)$ & $13(0.6)$ & - & $1(0.1)$ & - & $3(0.2)$ & $25(1.2)$ \\
\hline Tetracycline & $1(0.1)$ & $1(0.1)$ & - & - & - & - & $2(0.1)$ \\
\hline Total & 306 (15.1) & $1342(66.3)$ & - & $200(9.9)$ & - & $176(8.7)$ & $2024^{* * * * *}$ \\
\hline
\end{tabular}

${ }^{*}$ Antibiotics not listed in the guideline; ${ }^{* *}$ No clear statement regarding appropriate indication for the antibiotics; ${ }^{* * *}$ Antibiotics not listed in the guideline and no statement regarding appropriate indications; ${ }^{* * * *}$ Missing data in medical records; ${ }^{* * * * *}$ All percentages are given to one decimal place, so the total is not $100 \%$. 
Table 4. The appropriateness of antibiotic prescriptions according to guideline- 2 .

\begin{tabular}{|c|c|c|c|c|c|c|c|}
\hline \multirow{2}{*}{ Antibiotic } & \multirow{2}{*}{$\begin{array}{c}\text { Appropriate } \\
\text { N (\%) }\end{array}$} & \multirow{2}{*}{$\begin{array}{c}\text { Inappropriate } \\
\mathbf{N}(\%)\end{array}$} & \multicolumn{4}{|c|}{$\begin{array}{l}\text { Could not be classified } \\
\text { (Indeterminate: Id) }\end{array}$} & \multirow{2}{*}{$\begin{array}{l}\text { Total } \\
\text { N (\%) }\end{array}$} \\
\hline & & & Id $^{*}$ & Id $^{* *}$ & $\mathbf{I d}^{* * *}$ & $\mathbf{I d}^{* * * *}$ & \\
\hline Amoxicillin & $106(5.2)$ & $2(0.1)$ & $3(0.2)$ & 1362 (67.3) & - & $123(6.1)$ & 1596 (78.9) \\
\hline Ampicillin & - & - & - & - & $1(0.1)$ & - & $1(0.1)$ \\
\hline Cefadroxil & - & - & - & - & $2(0.1)$ & - & $2(0.1)$ \\
\hline Cephalosporin & - & - & - & - & $2(0.1)$ & - & $2(0.1)$ \\
\hline Chloramphenicol & - & - & - & - & $1(0.1)$ & - & $1(0.1)$ \\
\hline Ciprofloxacin & $7(0.4)$ & - & $2(0.1)$ & - & $18(0.9)$ & $3(0.2)$ & 30 (1.5) \\
\hline Clindamycin & $16(0.8)$ & - & $1(0.1)$ & $161(8.0)$ & $3(0.2)$ & $20(1.0)$ & 201 (9.9) \\
\hline Doxycyclin & $1(0.1)$ & - & - & - & $1(0.1)$ & - & $2(0.1)$ \\
\hline Erythromycin & $1(0.1)$ & - & - & $17(0.8)$ & - & - & $18(0.9)$ \\
\hline Lincomycin & $1(0.1)$ & - & - & $3(0.2)$ & $34(1.7)$ & $4(0.2)$ & $42(2.1)$ \\
\hline Metronidazole & $11(0.5)$ & - & - & $68(3.4)$ & - & $23(1.1)$ & $102(5.0)$ \\
\hline Spiramycin & $2(0.1)$ & - & - & $2(0.1)$ & $18(0.9)$ & $3(0.2)$ & $25(1.2)$ \\
\hline Tetracyclin & - & - & - & $1(0.1)$ & $1(0.1)$ & - & $2(0.1)$ \\
\hline Total & $145(7.2)$ & $2(0.1)$ & $6(0.3)$ & 1614 (79.7) & $81(4.0)$ & $176(8.7)$ & $2024^{* * * * *}$ \\
\hline
\end{tabular}

*Antibiotics not listed in the guideline; ${ }^{* *}$ No clear statement regarding appropriate indication for the antibiotics; ${ }^{* * *}$ Antibiotics not listed in the guideline and no statement regarding appropriate indications; ${ }^{* * * *}$ Missing data in medical records; ${ }^{* * * * *}$ All percentages are given to one decimal place, so the total is not $100 \%$.

Table 5. The appropriateness of antibiotic prescriptions according to guideline-3.

\begin{tabular}{|c|c|c|c|c|c|c|c|}
\hline \multirow{2}{*}{ Antibiotic } & \multirow{2}{*}{$\begin{array}{c}\text { Appropriate } \\
\text { N (\%) }\end{array}$} & \multirow{2}{*}{$\begin{array}{c}\text { Inappropriate } \\
\mathbf{N}(\%)\end{array}$} & \multicolumn{4}{|c|}{$\begin{array}{l}\text { Could not be classified } \\
\text { (Indeterminate: Id) }\end{array}$} & \multirow{2}{*}{$\begin{array}{l}\text { Total } \\
\text { N (\%) }\end{array}$} \\
\hline & & & Id $^{*}$ & $\mathbf{I d}^{* *}$ & $\mathbf{I d}^{* * *}$ & $\mathbf{I d}^{* * * *}$ & \\
\hline Amoxicillin & $113(5.6)$ & $2(0.1)$ & $1(0.1)$ & 1357 (67.1) & - & $123(6.1)$ & $1596(78.9)$ \\
\hline Ampicillin & - & - & - & - & $1(0.1)$ & - & $1(0.1)$ \\
\hline Cefadroxil & - & - & - & $1(0.1)$ & $1(0.1)$ & - & $2(0.1)$ \\
\hline Cephalosporin & - & - & - & - & $2(0.1)$ & - & $2(0.1)$ \\
\hline Chloramphenicol & - & - & - & - & $1(0.1)$ & - & $1(0.1)$ \\
\hline Ciprofloxacin & $9(0.4)$ & - & - & - & $18(0.9)$ & $3(0.2)$ & 30 (1.5) \\
\hline Clindamycin & $14(0.7)$ & $1(0.1)$ & $1(0.1)$ & $4(0.2)$ & $161(8.0)$ & $20(1.0)$ & 201 (9.9) \\
\hline Doxycyclin & $1(0.1)$ & - & - & $1(0.1)$ & - & - & $2(0.1)$ \\
\hline Erytrhomycin & $1(0.1)$ & - & - & $17(0.8)$ & - & - & $18(0.9)$ \\
\hline Lincomycin & $1(0.1)$ & - & - & - & 37 (1.8) & $4(0.2)$ & $42(2.1)$ \\
\hline Metronidazole & $11(0.5)$ & - & - & $68(3.4)$ & - & $23(1.1)$ & $102(5.0)$ \\
\hline Spiramycin & $2(0.1)$ & - & - & $3(0.2)$ & $17(0.8)$ & $3(0.2)$ & $25(1.2)$ \\
\hline Tetracyclin & - & - & - & - & $2(0.1)$ & - & $2(0.1)$ \\
\hline Total & 152 (7.5) & $3(0.2)$ & $2(0.1)$ & $1452(71.7)$ & 240 (11.9) & $176(8.7)$ & $2024^{* * * * * *}$ \\
\hline
\end{tabular}

*Antibiotics not listed in the guideline; ${ }^{* *}$ No clear statement regarding appropriate indication for the antibiotics; ${ }^{* * *}$ Antibiotics not listed in the guideline and no statement regarding appropriate indications; ${ }^{* * * *}$ Missing data in medical records; ${ }^{* * * * *}$ All percentages are given to one decimal place, so the total is not $100 \%$. 
Table 6. The appropriateness of antibiotic prescriptions according to guideline-4.

\begin{tabular}{|c|c|c|c|c|c|c|c|}
\hline \multirow{2}{*}{ Antibiotic } & \multirow{2}{*}{$\begin{array}{c}\text { Appropriate } \\
\text { N (\%) }\end{array}$} & \multirow{2}{*}{$\begin{array}{c}\text { Inappropriate } \\
\mathbf{N}(\%)\end{array}$} & \multicolumn{4}{|c|}{$\begin{array}{l}\text { Could not be classified } \\
\text { (Indeterminate: Id) }\end{array}$} & \multirow{2}{*}{$\begin{array}{l}\text { Total } \\
\text { N (\%) }\end{array}$} \\
\hline & & & Id $^{*}$ & Id $^{* *}$ & $\mathbf{I d}^{* * *}$ & $\mathbf{I d}^{* * * *}$ & \\
\hline Amoxicillin & $242(12.0)$ & $105(5.2)$ & $1126(55.6)$ & - & - & $123(6.1)$ & 1596 (78.9) \\
\hline Ampicillin & - & - & $1(0.1)$ & - & - & - & $1(0.1)$ \\
\hline Cefadroxil & $1(0.1)$ & - & $1(0.1)$ & - & - & - & $2(0.1)$ \\
\hline Cephalosporin & - & - & $2(0.1)$ & - & - & - & $2(0.1)$ \\
\hline Chloramphenicol & - & - & $1(0.1)$ & - & - & - & $1(0.1)$ \\
\hline Ciprofloxacin & $14(0.7)$ & $3(0.2)$ & $10(0.5)$ & - & - & $3(0.2)$ & $30(1.5)$ \\
\hline Clindamycin & $37(1.8)$ & $25(1.2)$ & 119 (5.9) & - & - & $20(1.0)$ & 201 (9.9) \\
\hline Doxycyclin & $1(0.1)$ & - & $1(0.1)$ & - & - & - & $2(0.1)$ \\
\hline Erytrhomycin & $2(0.1)$ & $2(0.1)$ & $14(0.7)$ & - & - & - & $18(0.9)$ \\
\hline Lincomycin & $7(0.4)$ & $5(0.3)$ & $26(1.3)$ & - & - & $4(0.2)$ & $42(2.1)$ \\
\hline Metronidazole & $18(0.9)$ & $5(0.9)$ & $56(2.8)$ & - & - & $23(1.1)$ & $102(5.0)$ \\
\hline Spiramycin & $6(0.3)$ & $2(0.1)$ & $14(0.7)$ & - & - & $3(0.2)$ & $25(1.2)$ \\
\hline Tetracyclin & $1(0.1)$ & - & $1(0.1)$ & - & - & - & $2(0.1)$ \\
\hline Total & 329 (16.3) & $147(7.3)$ & $1372(67.8)$ & - & - & $176(8.7)$ & $2024^{* * * * *}$ \\
\hline
\end{tabular}

*Antibiotics not listed in the guideline; ${ }^{* *}$ No clear statement regarding appropriate indication for the antibiotics; ${ }^{* * *}$ Antibiotics not listed in the guideline and no statement regarding appropriate indications; ${ }^{* * * *}$ Missing data in medical records; ${ }^{* * * * *}$ All percentages are given to one decimal place, so the total is not $100 \%$.

generally not done in this hospital, and this may explain why dental practitioners seemed to favor broad-spectrum antibiotics [14]. This may be one reason why as many as $54.1 \%$ of amoxicillin prescriptions were judged as inappropriate according to guideline-1. Antibiotics may also be prescribed for conditions that do not require them, such as pulpitis [15], and this can have an impact on the evaluation of treatment effectiveness [16].

According to the Health Ministry Regulation No HK.02.02/Menkes/068/2010, the Indonesian government encourages the use of generic drugs in government hospitals, and in this teaching dental hospital, $79.5 \%$ of antibiotic prescriptions referred to generic (official) names. Amoxicillin was the most frequently prescribed agent (78.8\%), even though it is not necessarily suitable for management of routine dental infection [17]. Nevertheless, it is widely used for infection management in dentistry [14]. Clindamycin was the second most prescribed drug (9.9\%). It should not be used routinely for treatment for oral infection management, because it is no more effective than penicillin against anaerobes, but it can be used to treat dento-alveolar abscess that has not responded to penicillin or metronidazole, because it is well distributed in soft tissues and bone [7]. Other drugs such as metronidazole, doxycycline and cephalosporin were quite rarely prescribed. In particular, doxycycline and cephalosporin are poorly absorbed, and routine use for dental infections is precluded [7].

In principle, antibiotics should be reserved for the management of active odontogenic infectious diseases and also considered for hematogenously spread infections such as endocarditis infection (EI) in some high-risk dental patients [12]. In this connection, it is noteworthy that pulp gangrene and pulp necrosis were the two most common diagnoses in the study hospital (26.7\% and $8.8 \%$, respectively). Regarding these conditions, there is no scientific basis for recommending systemic antibiotics, although of course antibiotics may be prescribed if there are signs and symptoms of infection. This may be another reason for the high level of inappropriate prescriptions according to guideline-1. It is also possible that inappropriate antibiotic prescribing in our study setting is partly due to cultural beliefs and patients' expectations or perhaps to prescribers' lack of confidence in their dental skills [18].

Another important point is that the various guidelines are not necessarily compatible or fully evidence-based. It is noteworthy that even with guideline- 1 , we could not assess the appropriateness of $9.9 \%$ of prescriptions, while the other three guidelines were not able to evaluate the appropriateness of most (67.8\% - 84.0\%) prescriptions. These guidelines seem to be of limited practical value to guide dental practitioners' choice of drugs to 
prescribe. There is an urgent need for randomized controlled trials with objective outcome measures to provide scientifically based guidelines for best practice [18]. The American Dental Association [19] guideline emphasizes the need to: 1) make an accurate diagnosis; 2) use an appropriate antibiotic and dosage; 3) consider using narrow-spectrum antibiotic drugs in simple infections to minimize disturbance of normal microorganisms; 4) avoid treating viral infections; 5) attempt to conduct sensitivity or microbiological testing; 6) consider possible adverse effects; 7) educate and inform patients regarding proper use and emphasize the importance of completing the full course of antibiotic therapy in dental infections.

On the basis of our findings, we offer the following recommendations: 1) There should be greater internal control of the prescription of antibiotics in Indonesian hospitals through the development of detailed individual institutional guidelines; 2) There should be further education and training of dental practitioners concerning appropriate prescription of antibiotics, especially among co-assistants; 3) Sustained management and policy support are needed to involve consumers and stakeholders.

\section{Conclusion}

This is the first study to investigate retrospectively the appropriateness of antibiotics prescribing by dental practitioners in an Indonesian dental teaching hospital. Our findings indicate that there is a substantial level of inappropriate antibiotics prescription, and also suggest that current Indonesian guidelines are inadequate to assess the appropriateness of antibiotics prescriptions in many cases. The baseline data gathered by this study should help dental practitioners and policymakers to improve prescribing practice, and highlight the need to develop specific institutional guidelines to encourage best practice in antibiotics prescription and to encourage continuing education of practitioners, especially students.

\section{Acknowledgements}

The authors would like to grateful to DIKTI (Higher Education) for doctoral course scholarship. We would like to thank the director and management of the dental teaching hospital for providing the data for this study.

\section{References}

[1] Kotwani, A., Chaundury, R.R. and Holloway, F.A.M. (2012) Antibiotic-Prescribing Practive of Primary Care Prescriber for Acute Diarrhea in New Delhi, India. Value in Health, 15, S115-S119. http://dx.doi.org/10.1016/j.jval.2011.11.008

[2] Kuyvenhoven, M.M., van Balen, F.A.M. and Verheij, T.J.M. (2003) Outpatient Antibiotic Prescriptions from 1992 to 2001 in The Netherlands. Journal of Antimicrobial Chemotherapy, 52, 675-678. http://dx.doi.org/10.1093/jac/dkg412

[3] Ashiru-Oredope, D., Sharland, M., Charani, E., McNulty, C. and Cooke, J. (2012) Improving the Quality of Antibiotic Prescribing in the NHS by Developing a New Antimicrobial Stewardship Programme: Start Smart-Then Focus. Journal of Antimicrobial Chemotherapy, 67, i51-i63. http://dx.doi.org/10.1093/jac/dks202

[4] Lockhart, P.B., Loven, B., Brennan, M.T. and Fox, P.C. (2007) The Evidence Base for the Efficacy of Antibiotic Prophylaxis in Dental Practices. The Journal of the American Dental Association, 138,458-474. http://jada.ada.org/content/138/4/458.full.pdf+html

[5] Akande, T.M., Ologe, M. and Medubi, G.F. (2009) Antibiotic Prescription Pattern and Cost at University of Ilorin Teaching Hospital, Ilorin, Nigeria. International Journal of Tropical Medicine, 4, 50-54.

[6] Palmer, N., Ireland, R. and Palmer, S. (1998) Antibiotic Prescribing Pattern of a Group of General Dental Practitioners: Result of a Pilot Study. Primary Dental Care, 5, 137-141.

[7] Aswapokee, N., Vaithayapichet, S., Heller, R.F. (1989) Pattern of Antibiotic Use in Medical Ward at Siriaj Hospital. Journal of Infectious Diseases and Antimicrobial Agents, 6, 79-82.

[8] Weinberg, M. and Froum, S.J. (2013) The Dentists’s Drug and Prescription Guide. 1st Edition, Wiley-Blackwell, UK.

[9] Scottish Dental Clinical Effectiveness Programme (2011) Drug Prescribing for Dentistry. 2nd Edition, Scottish National Health Service.

[10] Cambridgeshire National Health Science (NHS) Antibiotic Prescribing Guidelines for Dentists. http://extranet.cambridgeshire.nhs.uk/Downloads/Healthcare\%20Governance/Dental\%20information/Antibiotic\%20Pr escribing\%20guidelines\%20for\%20Dentists.pdf

[11] National Guideline Clearinghouse (2008). http://www.guideline.gov/content.aspx?id=47399\&search=impacted+teeth

[12] Dajani, S.A., Taubert, K.A., Wilson, W., et al. (1997) Prevention of Bacterial Endocarditis. Circulation, 96, 358-366. 
http://dx.doi.org/10.1161/01.CIR.96.1.358

[13] Afssaps (2012) Recommendations for Good Practice, Precription of Antibiotic for Oral and Dental Care. Médecine et Maladies Infectieuses, 42, 193-212.

[14] Roda, R.P., Bagan, J.V., Bielsa, J.M.S. and Pastor, E.C. (2007) Antibiotic Use in Dental Practice. A Review. Medicina Oral, Patología Oral y Cirugía Bucal, 12, E186-E192.

[15] Gour, R.P., Kohli, S., Advani, U., Kulshreshtha, A.J. and Parakh, R. (2013) Prescription Pattern of Antimicrobial Agents by Dental Practitioners: A Questionnaire Based Study. International Journal of Basic \& Clinical Pharmacology, 2, 311-314.

[16] Adorka, M., Honore, M., Lubbe, M., Serfontein, J. and Allen, K.(2013) The Impact of Appropriate Antibiotic Prescribing on Treatment Evaluation Parameters. Journal of Public Health in Africa, 4, e2. http://dx.doi.org/10.4081/jphia.2013.e2

[17] Karlowsky, J.A., Zhanel, G.G., Davidson, R.J. and Hoban, D.J. (1994) Once-Daily Aminoglycoside Dosing Assessment by MIC Reversion Time with Pseudomonas aeruginosa. Antimicrobial Agents and Chemotherapy, 38, 1116511168. http://dx.doi.org/10.1128/AAC.38.5.1165

[18] (2012) Personal Interview. Unpublished

[19] Roy, K.M. and Bagg, J.(2000) Antibiotic Prescribing by General Dental Practitioners in the Greater Glasgow Health Board, Scotland, British Dental Journal, 188, 647-676. http://dx.doi.org/10.1038/sj.bdj.4800574a http://dx.doi.org/10.1038/sj.bdj.4800574 